\title{
Holophrastic Utterances: Types and Meaning Dimensions in Igbo
}

\section{Aloysius U. Umeodinka and Edith U. Nwobu \\ https://dx.doi.org/10.4314/ujah.v22i2.3}

\section{Abstract}

Linguistics, in its study of language, brings out the essential role communication plays in the daily lives of human beings. The roles are particularly revealed in semantics, the study of meaning. These meanings have as much different shades as they are used for interaction at the different levels of word, phrase and sentence. It is against this background that this paper focuses on "Holophrastic Utterances: Types and Semantic Dimensions in Igbo". One of the objectives of the study is to make known the meaning of adult holophrastic expressions. The study is also purposed to categorize such utterances, reveal their contexts of usage and their dimensions of meaning in Igbo. The approach adopted for the study is descriptive. And it is the Use Theory of Meaning that guides the study. The research discovers that adult holophrastic utterances are such that go beyond the involvement of children's type of simple one-word utterances used in their stages of development to embrace the use of such single words by adults to reveal the social or common background they share in their interactional relationships. It is the expression of a complex of ideas in a single word or in a fixed phrase. The holophrastic utterances have been discovered to be classifiable into interrogative, affirmative, consolatory, greeting, appeal, appreciative, disapproval, advisory, imperative and condemnation. It has also been found out that the names of the different classes are synonymous with their contexts and purposes 
of employment in communication. Also found out is that their dimensions of usage can be overlapping and not always fixed.

Keywords: holophrases, utterances, semantics, dimensions

\subsection{Introduction}

The study of linguistics is very enriching. With the phonetics aspect of it, one can learn an accent that is not native to him and also how to speak another language using accurate pronunciations. With its phonology, one can discover the principles governing the organization of sounds in languages as well as, be able to explain the variations that obtain. Then, with its segment of morphology, one can learn not only the breaking down of morphemes and decoding their meanings, but also augmenting of one's vocabulary. With the study of syntax, one can comprehend how languages work as well as help language learners to understand the patterns of a language effectively and clearly. And with semantics, one can propose precise meanings of words and phrases and remove confusion which might mislead readers in their comprehension.

Of all these benefits accruable from the study of linguistics, the aspect that is attractive to us in this study is pragmatics, through which we can get acquainted with how language is used to do things and the ability to define a lot of conditions that surround an utterance or text. It is on the basis of this point of attraction that this research topic is on "The Holophrastic Utterances: Types and Semantic Dimensions in Igbo".

One of the cardinal objectives of the study is to unfold the meaning of adult holophrastic expressions. The second objective is to classify them. The third is to expose their contexts of usage. The fourth and final objective is to explore their various dimensions of 
meaning in Igbo. These objectives are pointers to this study's focus on the speech act theory whose major concern is to analyse the roles which utterances play in relation to the behaviour or attitudes of the speakers and hearers in interpersonal communication.

In our bid to do a thorough job in this research, we plan to employ a categorical scheme that will address the characteristics of the population or the situation under study. This implies that our research method is going to be descriptive. The theory that will guide the study is the Usage, Contextual or Operational Theory of Meaning by Wittgenstein (1953).

To ensure a procedural work organization, the first section is the introduction. This is where we are going to usher in our reader/s to the purpose, prompting and the extent of the study. After the introduction, what follows is the literature review in section two. It is here that the written works of experts will be analysed along the line of our objectives and their relationships with our topic of research. It is from the analyses that we hope to make some deductions for opinion forming as they address the objectives of the study. Section three is for the analysis of findings. It is billed to concentrate on the procedural analysis of the deductions in line with the research objectives. Each of the objectives has to be revisited and analysed to arrive at some findings. These findings to the objectives will be summarily assembled in section four, where, also, the conclusion of the work will be made.

This research work is not hoped to leave the reader where it found him. Instead, it will open another vista of knowledge about the Igbo language. Among other things, the acts theory and its role and significance in language will be appreciated the more. Also, the association of single phrases with one meaning and with 
children alone will become otiose and out of fashion, as a contribution of this research. And most significantly, the knowledge of many Igbo people will be semantically broadened; as they get exposed to the multifarious facets of meaning that are attributed to numerous Igbo holophrastic verbalizations.

\subsection{An Overview of Literature}

This section is for carrying out an analytical survey of the written works that pertain to the subject of the research.

\subsection{Holophrastic Utterance}

Agbedo (2015) talks about Developmental Linguistics, the study of which studies is about how a child gradually improves in linguistic ability, especially in the acquisition of language in childhood. Supporting this view, Fromkin, Rodman and Hyams (2005: 325) bring in the idea of "holophrastic stage" (as when)" most children go through a stage in which their utterances consist of only one word. This is called the holophrastic stage from holo, "complete" or "undivided", and phrase, "phrase" or "sentence", because these one-word utterances seem to convey a more complex message". For instance, at this stage, when a child says "down", that child may be passing across a request to be put down, or the child be saying something on a toy that has fallen down.

\section{Igbo Holophrastic Utterances}

It is helpful that the words of Echebima (2015: 92) be used to talk about Igbo holophrastic utterances. According to him, they "are single words which serve to convey complete idea or statement on their own. People associate such single-word statements with 
children, but in the Igbo language, it is a common, daily, social utterance for all".

Echebima (2015: 92) goes ahead to offer some examples of such holophrastic utterances in English and the equivalents or explanations in Igbo. Such of his examples include the following: Accept my sympathy $=$ Ndo, Be careful $=$ Nwayọo, , Don't worry $=$ Esogbula , Excuseme, may I pass = chere/cheretu, God forbid bad things $=$ tụfị/tụfịakwa, How many? $=$ ole/one?, How are you $=$ kedụ?/Annaa?/olịa? Aghaa?, I am sorry = Ndo/gbaghara, Is that so/ is that true $=$ Ezieokwu!I accept what you said $=00$, I will do as you said $=$ oo, wdg.

Writing about function elements in Igbo, Emenanjo (2015) insists that, based on inherent semantics and roles, holophrases should fall into the class of Igbo free and bound forms. And Emenanjo (2015: 11) defines holophrase as "ontologically a sentence which expresses notions like greetings, exclamations, responses, reactions, questions".

With these explanations from Echebima (2015) and Emenanjo (2015), it is easy to infer that holophrases in Igbo are not restricted to children. Adults also make holophrastic utterances of adults (and not children) that the topic of this research is set to address.

Emenanjo (2015) describes holophrases to be in the same group with ideophones, noun modifiers, conjunction, clitics, affixed, bound verb complements and infinitives. He groups all of them as bound roots.

According to Emenanjo (2015), holophrases, in Igbo, are grouped under exclamatory sentences. He maintains that, as exclamatory constructions, holophrases are used in expressing 72 
emotions, feelings or surprise, and that they are frequently used to introduce exclamatory sentences. He also is of the opinion that the statements, which comes after holophrases can be affirmative or negative.

Emenanjo's (2015) definition of holophrases is that they are one-word verbless sentences or ontological statements, and that they do not possess any traceable sentence elements. They do not have margins and have no verbs or NPs. He goes ahead to bring out a classification of them.

\section{Features of Holophrastic Utterances}

In terms of their features, holophrastic utterances have the tendency to possess, idiolectal and/or dialectal variations. Holophrases are capable of being nominals or verbals, and any of them can function as single-word sentences. It is possible for what are considered as holophrases here to be perceived as either interjections or exclamations in traditional grammar. Another feature of holophrases is that, just like ideophones, they begin with consonants. One other outstanding feature is that holophrases are often associated with non-verbal and paralingistics features. This means that body and eye movements, and, at times, some extremely low or even high voice pitches (Emenanjo, 2015).

The fact of being different dialectally and/or idiolectally is an obvious feature of holophrases. With the exception of such ones as "Esogbula, chere/cheretu" it is obvious that holophrases are verbless. Yes, in traditional grammar, they can be seen as interjections and exclamations. They are single wore sentences. They are more of nominals than verbals. They can begin with consonants, vowels or syllabic nasals and have paralinguistic features. 


\section{Classification of Holophrases in Igbo}

The holophrastic utterances, as listed by Echebima (2015: 92) are not grouped or classified. But the examples from Emenanjo (2015) are classified into greeting-words, response-words, reaction words, exclamation-words, call-words, oath words, and question-words, seven of them.

Some of the examples of greeting words are Biko (please, Nnọo (welcome) daalụ (thank you) or (keep at your work/keep it up). Response words are mba (no, not at all), Aa, Ee, oolo, iseo, yaa, etc. The examples of reaction words include $\mathrm{Aa}$ (What), Oo (what), Ndo (I am sorry), ntọọ/ntọọ = look, I told you so); Exclamation - words, Haa, Hoo, Hee, Hewo, chei, chee, Ahaa, ohoo, Ehee, olololoo (o), good god, my gosh i see; Taataa/Taa $\rightarrow$ keep quite; Call - words, as holophrases, include: Here, Hei (Kai), shaa); The oath - words are mbaa (I place my trust in) Tụfịa (god forbid; The question-word example is gbọo (is it not so?)

\section{Research Methodology and Theoretical Framework}

This research adopts the descriptive method of research. In other words, what is used as a guide for decision making is also determined by our description of the characteristics of the population or the phenomenon we are studying. By this, we are concentrating our research on the description of the subject of the research and not on why it occurs.

Another significant factor in the research methodology for this work is that the researchers are Igbo natives and intuitive 
speakers of the Igbo language. They are also versed in the knowledge of both linguistics and the Igbo language.

\section{Theoretical Framework}

The theoretical framework that guides this research is Wittgenstein's (1953) use, contextual or operational theory of meaning. According to Ndimele (1999) one of the objectives of the theory is to show that we cannot regard meanings as entities irrespective of whether they are physical or mental images. The main thrust of the theory is that any linguistic expression, whether it is a word, phrase or sentence, should be based on the context in which it is used. That is to say, the effect or effects that an expression creates in a specific context is what determine the meaning of such an expression (Ndimele, 1999).

Supporting this view, Ogbulogo (2005: 27) maintains that "the meaning of a word or an expression is determined by the context of its use". This also implies that in most cases the meaning of a word is its use. It is not just what you say, it is the way that you say it and the context in which you say it, that words are how you use them. That is, its full meaning in the language is characterised in terms of its use in the language.

\subsection{The Analysis of Findings}

We shall herein address the different objectives of the study analytically, one by one.

\subsection{Unfolding the Meaning of Adult Holophrastic Utterances}


In terms of meaning, as established in our literature review, holophrastic utterances are linguistic expressions in the form of single words which serve the purpose of conveying a complete message or idea unaided. They are characterized by being idiolectal, dialectal, being nominals, mostly non-verbal, paralinguistic and being in the form of interjections or exclamations.

\subsection{The Classification of Holophrastic Utterances}

Through our deductions from the description of the characteristics of the phenomenon of holophrases, we have come up with the following thirteen classes of holophrastic utterances in Igbo. Emenanjo (2015) has six classifications of holophrases. They are: words of greeting/salutation, words of response, words of reaction, words of exclamation, words for calling/call, words for interrogation while the present work added the following seven classifications: words of affirmation, words of blame, words of consolation, disapproval/refusal, words of condemnation, words of appreciation and words of appeal. Also six more words are added to the only word, 'gbọo' under Emenanjo's words of interrogation.

\subsection{Words of greeting/salutation}

There are words used often in the acknowledgement or expression of goodwill, especially on meeting. It serves words of honour or courteous recognition.

(1) Examples:

(i) $\mathrm{Kaa} \rightarrow$ good morning/good day/how are you? 


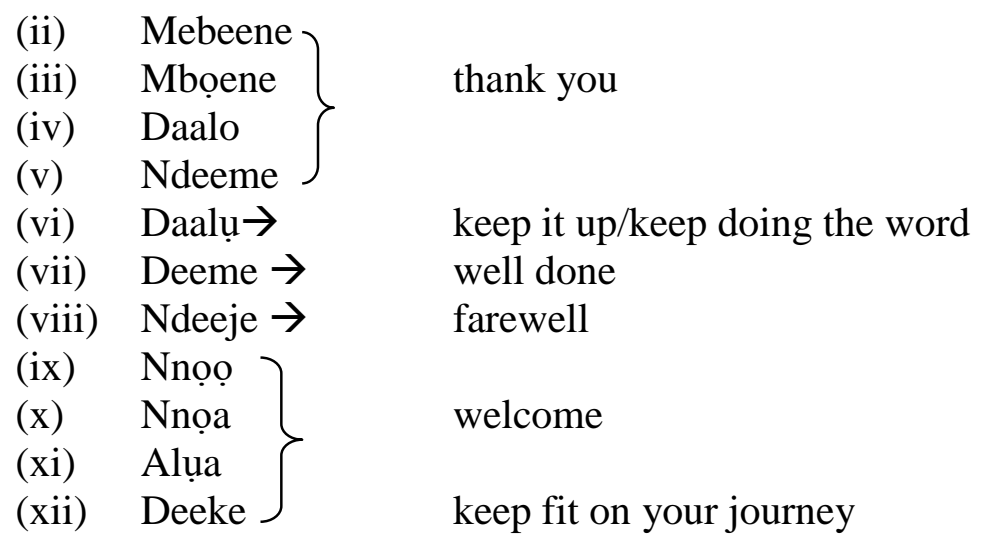

The words here are majorly from the dialects, except for the standard variety, 'daalụ' and 'nnọọ'.

\subsubsection{Words of response}

In the event that somebody intends to answer to a question posed by another person, the following may emerge as words of reply.
(i)
Aa
(ii) $\mathrm{Mba}$
No; Not at all
(iii) $\mathrm{Ee}-\mathrm{e}\}$
$\begin{array}{ll}\text { (v) } & \text { Yaa } \\ \text { (vi) } & \text { Iyaa }\end{array}$
(vii) Iseo $\} \quad$ Yes (in deed)
(viii) Ise
(ix) Owe

3.4 Words of reaction: When somebody says something or feels in a certain way and then makes an expression, his/her 
counterpart will show his specific emotion because of what happened using such words as these:

(ii) $\left.\begin{array}{l}\mathrm{Aa} \\ \mathrm{Oo}\end{array}\right\}$ What?!

(iii) Ndo $\rightarrow$ I'm sorry; what a pity

$\left.\begin{array}{ll}\text { (iv) Ntọọo } \\ \text { (v) Ntoso }\end{array}\right\}$ Look, I told you

\subsection{Words of Affirmation}

A positive reply to a question is an affirmation. In that case, the following utterances serve the purpose:

(i) $\quad$ Oo $\rightarrow$ I agree

(ii) $\mathrm{Iya} / \mathrm{Ee} / \mathrm{Eye} / \mathrm{gbem} \rightarrow$ yes, it is so

(iii) Ehee $\rightarrow$ I see

(iv) Ngwa $\rightarrow$ Am ready/ let's start

\subsection{Words of Exclamation}

Words of exclamation are such words that show a sudden cry or remark expressing surprise, strong emotion or pain.

Examples: (i) (H)aa, (ii) (H)oo, (iii) (H)ee, (iv) (H)ewo, (v) chei, (vi) chee, (vii) ahaa (viii) 'Ehee' (ix) 'Ololoololo(o)'. These expressions do not have a particular meaning. Their meaning is dependent on whether what was reacted to is positive or negative. For example, 'Haa!' or 'Aà!' could mean what a mess, why now, wonderful and so on, depending on the situation. 


\subsection{Words of Blame}

Words of blame are the ones that deolare somebody or something responsible for a fault.

Examples: Ntọo (ọ), Ntọọ = Look, I told you it will occur; $\mathrm{Ta} / \mathrm{Taa} / \mathrm{Taa} \rightarrow$ Keep quiet/stop doing/saying that

\subsection{Words for calling/call}

These are words crying out, shouting, yelling, screaming or shrieking.

Examples: (i) Hee/Hei/Kai/shaa $\rightarrow$ Hey you.

\subsection{Words for interrogation}

Interrogation is about questioning, cross-examination, quizzing, probing or inquisition, such as
(i) Gboọ? $\rightarrow$ Is it not so?
(ii) Ole/one? $\rightarrow$ How many?
(iii) Ole/one? $\rightarrow$ How much?
(iv) Kedụ/aghaa/ọha/Anaa? $\rightarrow$ How are you?
(v) Onye? $\rightarrow$ who?
(vi) Ebee? $\rightarrow$ Where?
(vii) Eziokwu? $\rightarrow$ is that true/so?

\subsection{Words of consolation}

Words of consolation are the ones of comfort received by a person after a loss or disappointment.

Examples:

(i) $\quad \mathrm{Ndo} \rightarrow$ Am sorry

(ii) Esogbula $\rightarrow$ Don't worry

(iii) Kasie $\rightarrow$ Take courage

(iv) Dibe/Diwe $\rightarrow$ Please, endure 


\subsection{Disapproval/Refusal}

Disapproval is an expression of unfavourable opinion.

Examples: (i) Mba $\rightarrow$ No. (ii) Ee-e $\rightarrow$ I don't agree; Not at all (iii)

Oolo $\rightarrow$ No; Not at all (iv) Ugha/Asị $\rightarrow$ False/It is not true.

\subsection{Words of condemnation}

This is an expression of disapproval over a thing that causes disgust or loathing; a feeling of hatred of an action.

Examples: (i) Tụfịa/Tụfịakwa $\rightarrow$ God forbid bad things

(ii) Arụ $\rightarrow$ An abomination

(i) Mpụ $\rightarrow$ An abomination

\subsection{Words of appreciation}

This is about the recognition and enjoyment of the god qualities of someone or something. It has to do with cherishing or treasuring. Examples: (i) Daalụ $\rightarrow$ Thank you (ii) Ndeeme $\rightarrow$ Thank you (ii) Anwụchulà $\rightarrow$ never mind, don't bother, don't mention it (iv) Ndeewo $\rightarrow$ Thank you.

\subsection{Words of Appeal}

Appeal is about making a serious, urgent, or heartfelt request. Examples: (i) Biko $\rightarrow$ please (ii) Ndo $\rightarrow$ Sorry, please forgive. (iii) Ewezilā $\rightarrow$ please, don’t be angry again.

\subsection{Analysis of the Contexts of Usage}

In pragmatics, we analyse meaning based on utterances. It is the linguistic discipline that takes account of the manner in which language is employed in indicating what somebody really means in 
specific situations, especially when the actual words used may tend to mean something different. In pragmatics, meaning is related to the context of utterance. In it, language is seen as an action performed by the speaker. What decides the meaning of an utterance of a speaker is therefore the action and the way of the utterance by a speaker.

Once a sentence is uttered, a speech act is performed, and this speech act depends on the context or conditions prevailing at the time the utterances were made. The type of utterance is determined by what knowledge the hearer has about the speaker. That is to say, the context is made up of the speaker, the hearer and the sentence. What this means is that the social context of an utterance maybe limited to social pleasantries, religious settings or to such factors like age, sex, or class of speakers.

\subsection{Types of Holophrastic Utterances Reflect their Contexts of Usage}

From the classification above, we have the context of response to a question, the context of reaction when somebody expresses an emotion, the context of affirming to a request and the context of exclamatorily expressing a surprise or strong emotion, the context of declaring somebody responsible for a fault. Others are the context of calling or screaming, the context of consolation, the context of disappointment, the context, of using expressions of disapproval, advices, appreciation and appeal. Each of those contexts is characterised by paralinguistic expressions.

\subsection{Summary of Findings and Conclusion}

This research work was started with the aim to look into holophrastic utterances in Igbo. The four objectives, to unfold the 
meaning of adult holophrastic expressions, to categorize the holophrastic utterances, and to expose their various contexts of usage.

We have seen that holophrastic expressions are such that indicate a complex of ideas in a single word or in a fixed phrase. The adult holophrastic expressions are idiolectal and dialectal, known to be in use in Igbo, consist of greeting word, responsewords, reaction-words, affirmation-words, exclamation-words, blame-words, call-words, interrogation words, consolation words, disapproval words, condemnation-words, advice-words, appreciation-words and appeal words. Most of these are known to be idiolectal and dialectal.

These categories of holophrases are indentified to represent diverse idiolects and dialects. Even at that, the different types of holophrastic expressions constitute in themselves, each as the contexts of usage. The implication is that there are as many types of holophrastic expressions as there are contexts in the Igbo usage of holophrastic utterances.

Further still, in the analysis of the semantic implications of the contexts of usage, it has been established that most of the holophrastic utterances do not have only one meaning. There are complex meanings, ideas and information embedded in the different contexts of usage of the holophrastic utterances.

\subsection{Conclusion}

The findings of this research have shown that all the objectives that prompted the research have been accomplished. Holophrastic utterances have been explained and classified. Their various contexts have been disclosed. 
With this accomplishment, this study has enriched the Igbo language. It has revealed that it is not only children that can lay claim to the use of holophrastic utterances. Among other things, this study has not only enriched Igbo semantics, but also has provided a dependable source of materials for further researches in Igbo semantics.

Dr. Aloysius Umeodinka is of the Department of Igbo, African \& Communication Studies, Nnamdi Azikiwe University, Awka au.umeodinka@unizik.edu.ng

Edith Ukamaka Nwobu teaches at the Department of Igbo, African \& Communication Studies, Nnamdi Azikiwe University, Awka. eu.nwobu@unizik.edu.ng 


\section{References}

Agbedo, C.U., (2015). General Linguistics: Historical and Contemporary Perspectives.Nsukka- Nigeria:KUMCEENtaeshe Resources.

Anagbogu, P., Mbah, B.M. \& Eme, C. (2010). Introduction to Linguistics. Awka: Amaka Dreams

Echebima, G. (2015). A Textbook of Igbo Linguistics. Owerri: Assumpta Press.

Emenanjo, N. (2015). A Grammar of Contemporary Igbo (Student's Edition). PortHarcourt:M \& J Grand Orbit Communication Ltd.

Ndimele, O. (2005). Semantics and the Frontiers of Communication. PortHarcourt: University of Port Harcourt Press.

Ofoegbu, C.O. (2008). Syntax: An Introductory Text. Enugu: Malchjay Publishers Ltd.

Ogbulogo , C. (2005). Concepts in Semantics. Lagos: Sam Iroanusi Publications.

Umeodinka, A.U. (2020). Introduction to Contrastive Studies (Igbo and English). Awka: DivinePress.

Wittgenstein, L. (1953). The Philosophical Investigations. Oxford: Blackwell. 